\title{
"Isso é Cris Ronaldo": Representações de masculinidade na Copa do Mundo do Jornal Folha de São Paulo
}

"Eso es Cris Ronaldo": Representaciones de masculinidades en la Copa del Mundo del Periódico Folha de San Pablo "This is Cris Ronaldo": Representations of masculinity during the World Cup in the Newspaper Folha de São Paulo

André Luiz dos Santos Silva

Universidade Federal do Rio Grande do Sul - UFRGS,

Porto Alegre-RS, Brasil

andrels@ufrgs.br

(iD https://orcid.org/0000-0002-9838-2558

\section{Janaina Andretta Dieder}

Universidade Feevale, Novo Hamburgo-RS, Brasil

janaina.dieder@gmail.com

(iD https://orcid.org/0000-0003-0854-6676

\section{Rafael Goulart Dullius}

Universidade Feevale, Novo Hamburgo-RS, Brasil

rafaelgoulart_90@hotmail.com

(D) https://orcid.org/0000-0001-7300-4908

\section{Gustavo Roese Sanfelice}

Universidade Feevale, Novo Hamburgo-RS, Brasil

sanfeliceg@feevale.br

(D) https://orcid.org/0000-0003-0159-3584

\section{Resumo:}

Este texto analisa um conjunto de publicações que representam o jogador da seleção portuguesa Cristiano Ronaldo como dissonante dos códigos de conduta prescritos para o Futebol. Para tanto, toma a cobertura do jornal Folha de São Paulo, ao longo do período dos jogos da Copa do Mundo FIFA/Brasil/2014, como espaço de produção do material empírico. Agrupadas, as publicações que tematizavam Cristiano Ronaldo foram analisadas a partir dos pressupostos da categoria Gênero e do conceito de representação. Ao longo do processo de produção e organização do material empírico, foi possível perceber que as publicações sobre o atleta português estiveram vinculadas à coluna "Copa e Cozinha", local especialmente pensado para tratar com irreverência dos acontecimentos da Competição. Evidenciado como egocêntrico, extravagante, vaidoso e adepto às práticas de autocuidado e embelezamento, consideradas excessivas, Cristiano Ronaldo parece romper com alguns códigos de conduta prescritos para/ pelo esporte. Desse modo, a coluna "Copa e Cozinha" faz uso da "zuação" como um aparato que avalia, qualifica e julga o que é inapropriado e excessivo no atleta português, tecnologia que tem como finalidade a regulação das condutas e a manutenção de hierarquias de gênero.

PalaVras-Chave: Masculinidades dissonantes, Folha de São Paulo, Cristiano Ronaldo, Gênero, Esporte.

\section{Abstract:}

This text analyses a set of publishings that represent the Portuguese national team player Cristiano Ronaldo as someone dissonant from the conduct codes prescribed for Soccer. Therefore, it adopts the coverage of the newspaper Folha de São Paulo during the 2014/Brazil/FIFA World Cup matches as a space of empiric material production. The publishings that have Cristiano Ronaldo as their theme were grouped and analysed based on the assumptions of Gender category and representation concept. Throughout the process of production and organization of the empiric material, we perceived that the publishings about the Portuguese athlete 
were linked to the column "Copa e Cozinha", place specially designed to deal irreverently with the events of the competition. Evidenced as egocentric, extravagant, vain, and adherent to self-care and beautification practices, which were considered excessive, Cristiano Ronaldo seems to break some conduct codes prescribed for/by sport. Thus, the column "Copa e Cozinha" adopts a "mocking behaviour" as an apparatus that evaluates, qualifies, and judges what is inappropriate and excessive in the Portuguese athlete, technology that aims to regulate the conducts and the maintenance of gender hierarchies.

KeYworDS: Dissonant masculinities, Folha de São Paulo, Cristiano Ronaldo, Gender, Sport.

\section{INTRODUÇÃO}

O esporte é considerado um dos maiores fenômenos culturais contemporâneos e seu papel na sociedade moderna é de grande relevância, uma vez que está intimamente ligado ao corpo social, com capacidade de mobilização de valores simbólicos, políticos, ideológicos, econômicos e, sobretudo, de produção/circulação de representações (Mezzaroba, Messa \& Pires, 2011; Sanfelice, 2018).

Desse modo, os megaeventos esportivos podem ser entendidos como resultados do esporte enquanto fenômeno contemporâneo, ao mesmo tempo que o (re)produz e o reforça por meio de um conjunto de mecanismos, dentre os quais a mídia. De acordo com Damo e Oliven (2013), a produção discursiva da mídia esportiva é parte inseparável dos megaeventos, "uma vez que elas são responsáveis pela elaboração de narrativas - audiovisuais e escritas - que reconfiguram os espetáculos num registro ainda mais espetacularizado, ao alcance de um público ampliado" (p. 48).

Desse modo, a Copa do Mundo FIFA /Brasil/2014 ingressou na ordem do dia da mídia como "um fato social de enorme importância na cultura brasileira contemporânea e cujo acesso esteve estreitamente vinculado a seu caráter mediatizado" (Gastaldo, 2009, p. 362). Como condição necessária para sua realização e, sobretudo, para a exploração máxima de seu potencial, a Copa do Mundo recebeu constantes coberturas midiáticas, cujos investimentos e programações construíram diversos significados na relação com o campo esportivo.

A partir desses aspectos, entendemos que "pedagogias culturais" (Sabat, 2001) são produzidas na relação entre mídia, futebol e marcadores sociais, como classe, raça, sexualidade e gênero, um intricado e complexo processo que produziu/produz representações diversas associadas ao esporte. Historicamente, as práticas esportivas, de modo geral, e o futebol, em particular, estão associados ao universo masculino, o que tem gerado um conjunto de barreiras que afastam as mulheres e os homens que não correspondem a determinadas expectativas de masculinidade (Goellner, 2005; Bandeira, 2010). Tais fenômenos são indicativos das "pedagogias de gênero" (Louro, 2008) no currículo do futebol, o que tem sido produzido e agenciado na relação com diversas instâncias sociais, entre elas, a mídia.

Assim sendo, partindo do pressuposto de que o futebol está historicamente associado à produção e à manutenção de identidades masculinas heterocentradas, este artigo discute, no período da Copa do Mundo / FIFA/Brasil 2014, representações de masculinidades dissonantes produzidas pelo jornal de maior circulação nacional, “A Folha de São Paulo". Especificamente, tem como objetivo analisar um conjunto de publicações que representam o jogador da seleção portuguesa Cristiano Ronaldo como dissonante dos códigos de conduta prescritos para o Futebol.

\section{Referencial Teórico Metodológico}

De acordo com Berger (2002), a mídia não é apenas um intermediador de fatos, ela é, sobretudo, um selecionador que enfatiza e intervém, por meio de palavras e imagens, na construção simbólica dos acontecimentos. Desse modo, os produtos veiculados pela mídia "ressaltam alguns significados, ocultam outros, incorporam significados correntes em alguns grupos e os ampliam para toda a sociedade”, o que acaba 
"naturalizando" representações e operando no sentido da manutenção de uma dada relação de forças no interior da sociedade" (Gastaldo, 2009, p. 355).

Do mesmo modo, a cobertura midiática do campo esportivo não limita seus conteúdos aos elementos técnicos, táticos e performáticos do esporte. Os acontecimentos relacionados às "práticas corporais" (Silva, 2014) são refeitos dentro da lógica midiática, começando a elaborar sentidos e significados (Sanfelice, 2018), dentre os quais, destacam-se, neste texto, as produções de sentidos associadas às masculinidades dissonantes.

De acordo com Camargo (2016), a "dissonância" situa-se nas bordas entre o que é normativo e o que é considerado desvio da norma. Tomando o corpo e os gestos esportivos como categorias para pensar normalidade e abjeção, o autor situa a dissonância dentro de um vasto espectro de possibilidades de subversão da norma, afinal as práticas esportivas e os corpos por ele analisadas são marcados por uma infinidade de manifestações e formas. Neste texto, entretanto, ao tomarmos as representações de um jornal específico acerca de um único jogador (Cristiano Ronaldo), parece ser produtivo articular a noção de dissonância à de gradiente de normalidade. De acordo com Dal'igna (2011) e Lopes, (2009) os gradientes de normalidade buscam evidenciar gradações das posições ocupadas pelos sujeitos em decorrência dos diferentes graus de transgressão e suas intersecções com os marcadores sociais, o que ressalta os efeitos das relações de poder num processo de ordenação dos sujeitos e suas condutas. Para a produção deste artigo, a articulação entre dissonância e gradientes de normalidade foi produtiva uma vez que serviu para: a) identificar as representações de masculinidades desviantes das normas de gênero publicadas pela Folha de São Paulo e b) analiticamente, ordená-las em diferentes posições de transgressão.

Ao tomar as representações do atleta Cristiano Ronaldo na Folha de São Paulo, este texto coloca em debate um conjunto de códigos de gênero veiculados por um dos jornais de maior circulação no Brasil. Em 2014, ano de realização da Copa do Mundo FIFA/Brasil, a 'Folha' contabilizou uma média de 351.745 publicaçóes, maior média nacional naquele ano, o que indica prestígio e solidez do jornal e do grupo ao qual pertence. Além do jornal Folha de São Paulo, o "Grupo Folha" agrega empresa de conteúdo e serviços de internet, a UOL, a gráfica Plural, o Instituto de Pesquisa Datafolha, agência de notícias Folhapress e a Editora Publifolha, entre outras (Kuhn Junior, Castilhos, Montin \& Sanfelice, 2015).

Para o desenvolvimento deste estudo, foram acessadas as edições on-line da 'Folha' no período em que ocorreu a Copa do Mundo FIFA/Brasil/2014 - de 12 de junho a 13 de julho. Inicialmente foram identificadas as publicações referentes aos jogos e atletas participantes da Copa, cujas representações estivessem marcadas por masculinidades dissonantes. Nesse processo inicial, considerou-se o jornal como um todo, incluindo imagens, editoriais, painéis, títulos, capas, notícias, notas e seus diversos cadernos (Opinião, Poder, Mundo, Mercado, Cotidiano, Esporte, Ilustrada, Turismo, Guia Folha, Folha Invest, Folha Corrida, Caderno Tec e Folhinha).

A partir disso, foram encontradas dez publicações que evidenciam 'masculinidades dissonantes associadas ao futebol, das quais, cinco colocavam em evidência o jogador português Cristiano Ronaldo (Quadro 1).

QUADRO 1

A dissonância de Cristiano Ronaldo na Folha de São Paulo

\begin{tabular}{|c|c|c|c|c|}
\hline & AUTORIA & DATA & TÍTULO & PÁGINA \\
\hline $\mathbf{1}$ & Sandro Macedo & $12 / 06 / 2014 \mathrm{a}$ & Faça sua Tabela & D2 e D3 \\
\hline $\mathbf{2}$ & Sandro Macedo & $13 / 06 / 2014 \mathrm{~b}$ & Sexta-feira 13 & D2 \\
\hline $\mathbf{3}$ & Sandro Macedo & $16 / 06 / 2014 \mathrm{c}$ & Isso é Cris Ronaldo & D2 \\
\hline $\mathbf{4}$ & Sandro Macedo & $17 / 06 / 2014 d$ & Schumi na copa & D2 \\
\hline $\mathbf{5}$ & Sandro Macedo & $18 / 06 / 2014 \mathrm{e}$ & O que você já viu & D2 \\
\hline
\end{tabular}


Os processos analíticos deste texto tomaram como baliza os pressupostos da categoria gênero e do conceito de representação (Hall, 1997). Desse modo, as publicações da Folha de São Paulo foram tomadas em sua materialidade representacional sempre permeável à atribuição de sentidos e significados. Enquanto manifestações da cultura, as representações são concebidas como mecanismos de significação que produzem "verdades", nomeando, classificando e hierarquizando as coisas, as práticas, os sujeitos e os fenômenos. A representações, portanto, inserem-se no campo de lutas por significação e são constituídas na relação entre os sujeitos, conhecimento e poder, produzindo, como efeito, "realidades".

Neste texto, as representações de Cristiano Ronaldo, ao passo que produzidas em meio a sentidos e significados sobre as tradicionais condutas esperadas para homens atletas de futebol, (re)atualizam-se com base nos saberes informados por Gênero, conveniente e inapropriado.

O conceito de gênero, por sua vez, é entendido como "um organizador do social e da cultura" (Meyer, Klein, Dal'Igna \& Alvarenga, 2014, p. 900); "uma forma primária de dar significado às relações de poder” (Scott, 1995, p. 86), cujos mecanismos constroem, através de um conjunto de representações, lugares, hierarquizaçóes e expectativas que, ao mesmo tempo, incentivam e constrangem modos de ser e de se portar, produzindo, portanto, identidades. Cabe destacar, entretanto, que as identidades produzidas nos agenciamentos das relações de gênero são diversas, afinal são constituídas e constituintes de relações de poder, resistem, são resistidas e rearranjadas nas experiências das pessoas, produzindo outros modos de ser e de se portar (Anjos, 2015).

Nesse sentido, ao organizar o material empírico deste texto, a partir de publicações que representam o atleta Cristiano Ronaldo como desviante das normas de gênero para o Futebol, foi possível produzir análises em torno de um conjunto de tensionamento e transgressões aos códigos de conduta ensinados pelo esporte. Assim, o conceito de gênero articulado às noçóes de dissonância e de gradiente de normalidade constituemse como ferramentas teóricas eleitas para ajustar o foco e conduzir as análises que seguem.

\section{ENTRANDO EM CAMPO E RECONHECENDO O GRAMADO: REPRESENTAÇÕES DE GÊNERO E SeXualidade no futebol da Folha de São Paulo}

Nas publicações acessadas ao longo dos trinta dias de jogos, o Jornal Folha de São Paulo deu a ver um campo conflitivo sobre o qual foi possível perceber distintas representações de gênero. Mulheres e homens, em alguns momentos, foram colocados em posiçóes que a literatura acadêmica tem evidenciado como não convencionais quando se trata de Futebol masculino. A exemplo disso, as colunistas Ana Estela, Denise Fraga, Fernanda Torres e Tati Bernardi compõem um grupo de mulheres que comentam o futebol e seu contexto nas páginas da Folha de São Paulo. Em seus textos abordaram diferentes aspectos dos acontecimentos da competição, problematizando questões econômicas, o legado da copa, as eleições que se avizinhavam e a vitória por 7 a 1 da Seleção Alemã sobre a brasileira.

Apesar de serem maioria nas redações jornalísticas brasileiras, chegando a $64 \%$ dos profissionais, ocupando cargos de chefia e direção, nas editorias esportivas, as mulheres são minoria, assinando apenas $8 \%$ dos textos (Brum \& Capraro, 2015). Ainda que, desde a década de 1990, note-se um aumento do número de mulheres ocupando funções dentro do jornalismo esportivo, este campo naturalizado como masculino tem problematizado a legitimidade de saber das mulheres que 'ousam' comentar e escrever sobre esporte.

Além dos comentários e colunas assinadas por mulheres, os corpos masculinos também ocuparam lugares não convencionais para a mídia esportiva. No caderno "Copa", o artigo intitulado "Benza Deus", assinado por Roberto de Oliveira (2014, p. D10), apresenta, de modo erotizado e altamente objetificado, os "Gatóes da Copa":

Um porte atlético, um penteado descolado, aquele peito quase tão largo quanto o gol, sem falar nas coxas e nos bumbuns que inspiram sonhos eternos. [...] Dentro e fora do campo são muitos os atributos que mexem com a criatividade da torcida. 
Os "musos da copa ${ }^{1}$ " tiveram seus corpos expostos em poucos trajes, alguns somente vestindo roupa íntima, a maioria sem camisa. Com os músculos marcados sob a pele tatuada, as imagens evidenciam coxas e braços fortes e calibrosos, abdomes definidos e "bundas" torneadas ${ }^{2}$. Flagrados em poses sensuais, os corpos masculinos presentes no artigo de Oliveira nos fazem pensar o lugar comum da mídia esportiva feminina, cujo foco historicamente esteve ligado à beleza e sensualidade de seus corpos, colocando em segundo plano a competência no esporte (Schpun, 1999; Goellner, 2003; Figueiredo, 2013).

Se por um lado, os modos de representação aqui sinalizados indicam possíveis resistências e rearranjos das tendências que historicamente vieram se constituindo na mídia, por outro, o número e o espaço reduzido de tais publicações sugerem a prevalência das tradicionais referências de gênero no esporte.

Desse modo, no campo de disputas por significação e por regimes de verdade da 'Folha', também se evidenciou a beleza e a erotização como atributos primeiros dos corpos femininos. Embora tivesse em seu quadro de comentaristas mulheres expoentes no cenário midiático, como Ana Estela, Denise Fraga, Fernanda Torres e Tati Bernardi, citadas acima, em algumas matérias do jornal, as mulheres e seus saberes sobre o futebol foram questionados, ao passo que o suposto interesse afetivo e sexual em turistas estrangeiros foram evidenciados.

De modo semelhante, 'outras' masculinidades também foram representadas. Em tons jocosos, menções à homossexualidade foram feitas evidenciando 'desvios' na conduta masculina, localizando no centro os astros do espetáculo: atletas e espectadores - homens heterocentrados. Nesse processo, a Folha de São Paulo coloca em funcionamento a "tecnologia da zuação" (Sales \& Paraíso, 2013), um mecanismo que é acionado pelas (má)condutas dos jogadores e se manifesta invocando o riso e a brincadeira para evidenciar o que é inadequado para homens atletas de futebol.

\section{“CRIS Ronaldo": A “ZUAÇÃo” E A PRODUÇÃo DE MASCUlinidadeS DisSONANTES}

Ao longo dos jogos da competição, na Folha de São Paulo, o futebol foi incorporado a tradicionais colunas do Jornal, na medida em que outros locais foram produzidos especialmente para isso. É o caso da coluna "Copa e Cozinha" (Folha de São Paulo, 2020), de autoria de Sandro Macedo. Colaborador da 'Folha' desde 2001, em 2010 criou a 'bem-humorada' seção "Numerada", em que tratava de notícias ligadas à Copa. Reeditada em 2014, recebeu o nome de "Copa e Cozinha", sendo publicada nos períodos do mundial ${ }^{3}$.

Fazendo uso do trocadilho com a palavra Copa, o jornal já nos indica que as notícias sobre o evento seriam tratadas nos cômodos da casa destinados à guarda de utensílios domésticos e à preparação dos alimentos. Historicamente destinado à presença das mulheres e da 'criadagem', a copa e a cozinha são entendidas como os espaços da intimidade (Villar, 2010; Santana \& Monteiro, 2014), onde, não raras vezes, acontecem as conversas 'frívolas', as 'fofocas' e os desentendimentos entre parentes. Muitas vezes errantes e desqualificadas, as conversas de cozinha (Santana \& Monteiro, 2014) nos indicam o lugar do debate não oficial, não sério, portanto, autorizado. Assim, constitui-se a coluna assinada por Sandro Macedo, local do riso fácil, dos pormenores da notícia, da irreverência - um espaço em que se autoriza falar de produtos de beleza e cortes de cabelo adotados pelos jogadores: lugar da charge, da piada e da ironia. No período da Copa, no jornal Folha de São Paulo, local outorgado a questionar, avaliar, julgar e "zuar" as masculinidades em ação no futebol.

No dia 12 de junho de 2014 (Figura 1), a coluna convida seus leitores a produzirem uma tabela para acompanhamento dos jogos (Macedo, 2014a). Ao apresentarem os grupos de países que iriam se confrontar na primeira fase do campeonato, algumas nacionalidades foram destacadas, entre elas: Portugal. 
FIGURA 1.

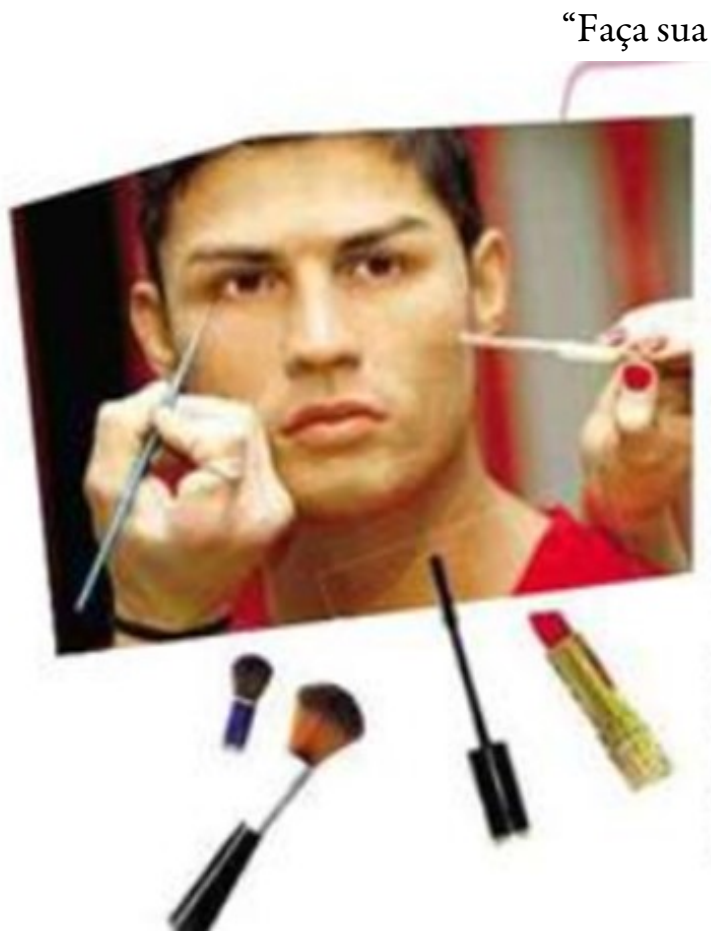

Teste do gel 1: Cris Ronaldo testará a força de seu gel em plena Salvador, às 13h. Recomendamos protetor solar fator 50 para CR7

Teste do gel 2: Cris Ronaldo vai a Manaus. A zona nunca será tão franca. Apesar do jogo ser às $19 \mathrm{~h}$, recomenda. mos protetor solar fator 40 para CR7

Teste do gel 3: Cris Ronaldo às $13 \mathrm{~h}, \mathrm{em}$ Brasília? Recomendamos fazer a sobran. celha pelo menos dois dias antes... e protetor solar fator 125 para CR7

Fonte: Macedo (2014a)- Folha de São Paulo, 12 de junho de 2014, p. D2

Símbolo máximo da equipe portuguesa, Cristiano Ronaldo é evidenciado em uma fotografia na qual seu rosto está ao lado de diversos instrumentos de beleza. Assim, já no primeiro dia de jogos, a coluna anuncia um dos seus alvos prediletos, um fenômeno esportivo e midiático, cuja vaidade considerada 'excessiva' parece, em alguma medida, postular uma conduta inapropriada para um homem atleta de futebol.

Apesar de eleito três vezes melhor jogador do mundo pela FIFA, melhor jogador da União das Federações Europeias de Futebol e artilheiro da Liga dos Campeões da UEFA (2007/2008 - 8 gols em 11 jogos; 2012/2013 - 12 gols em 12 jogos; 2013/2014-17 gols em 11 jogos (Ronaldo, 2020), o foco da coluna não recai sobre seus feitos enquanto atleta, mas ao conjunto de práticas de autocuidado e embelezamento socialmente reconhecidas como próprias das mulheres e dos homens gays.

Eleito, em 2012, o atleta mais metrossexual do mundo, Cristiano Ronaldo, juntamente com David Beckham e Ian Torpe compóe um conjunto de atletas de alta performance, cujos cuidados com o corpo e a imagem têm sido divulgados e apropriados pelo mercado da moda, beleza e bem-estar (Hall, Gough \& Seymour-Smith, 2012). A midiatização de atletas metrossexuais ${ }^{4}$, de acordo com Hall e Gough (2011), estaria encorajando homens heterossexuais a adotarem práticas historicamente associadas às mulheres $\mathrm{e}$ aos homens gays, um fenômeno cujo efeito seria a produção de um lugar de gênero alternativo aos polos binários masculino/feminino. Tal processo, entretanto, parece ser resistido pelas publicações que tematizam Cristiano Ronaldo na coluna "Copa e Cozinha".

Apesar de ser atleta do mais masculino e heterocentrado dos esportes (Camargo, 2014), apesar da imagem de Cristiano Ronaldo ser associada a belas mulheres, apesar de ser homem, jovem, branco, europeu, heterossexual e um dos melhores e mais bem pagos jogadores de futebol do mundo, na "Copa e Cozinha" a metrossexualidade de Cristiano Ronaldo seria condição legítima para torná-lo alvo da "zuação".

Em 16 de junho de 2014, (Figura 2) o atleta foi tema quase exclusivo da coluna assinada por Macedo (2014c). Em tons jocosos, seu corpo é estampado no centro das páginas D2 e D3 e, por meio do título "Isso é Cris Ronaldo", a coluna "Copa e Cozinha” promete alguns detalhes sobre o maior destaque da Seleção Portuguesa. De acordo com o artigo (Macedo, 2014c, p. D2): "Conheça um pouco mais do craque mais 
amado (por ele mesmo) da história e principal responsável por qualquer coisa que aconteça com os patrícios na Copa."

FIGURA 2.

"Isso é Cris Ronaldo"

\section{- 8 COPA \& COZINHA \\ POR SANDRO MACEDO \\ ARTE DE GUSTAVO PEREIRA}

httrp://copaecozinha blogtollha.uol.com.br
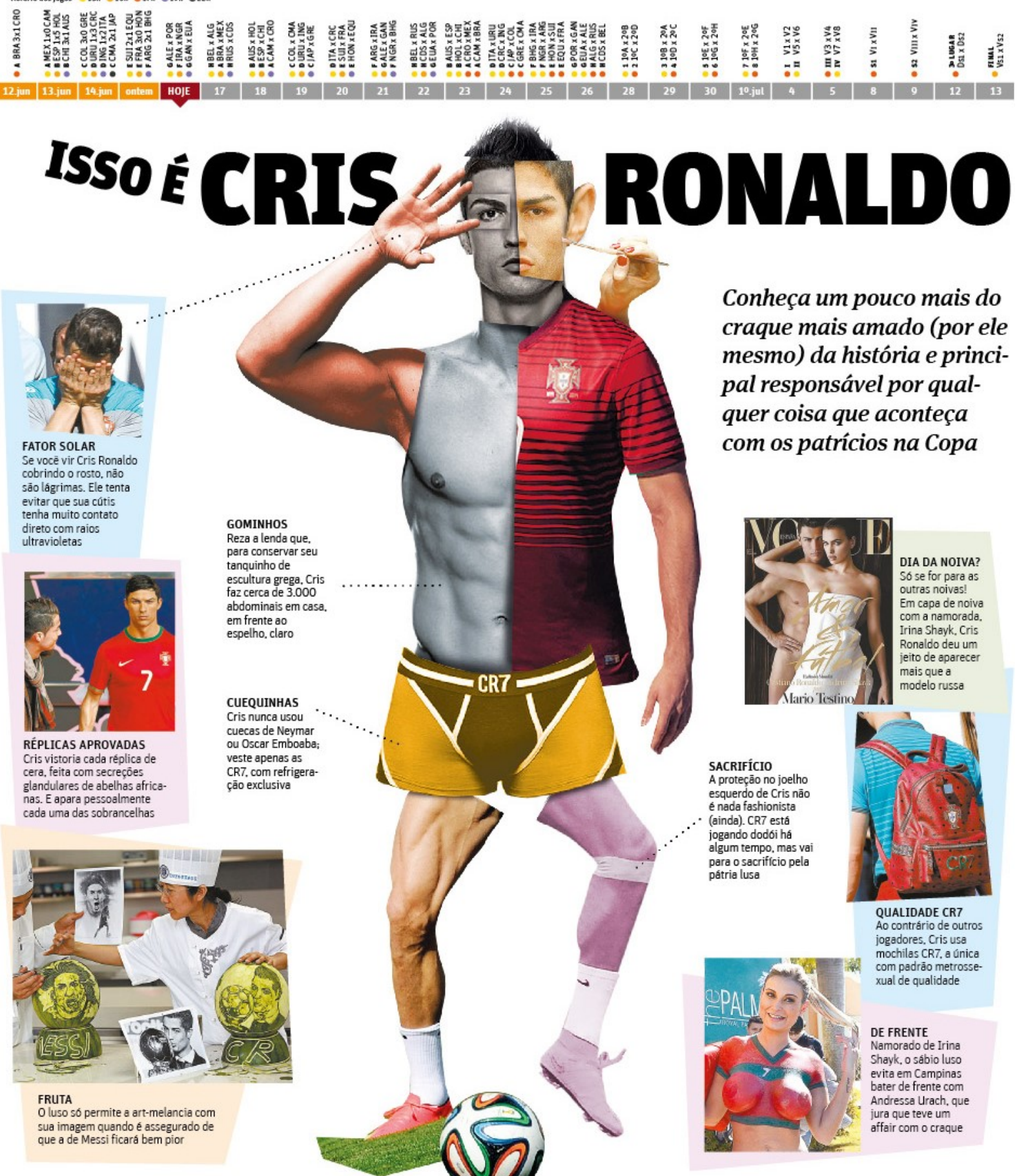

Conheça um pouco mais do craque mais amado (por ele mesmo) da história e principal responsável por qualquer coisa que aconteça com os patrícios na Copa Reza a lenda que, tanquinho de scultura grega, Cris bdominais em casa. spelho, claro

CUEQUINHAS cuecas de Neymar Oscar Emboab ( exclusiva

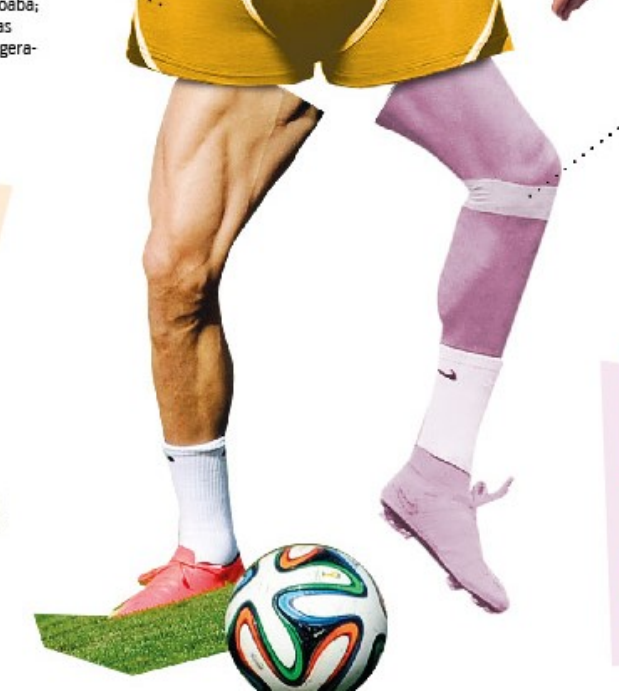

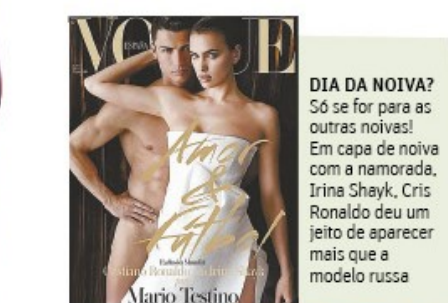

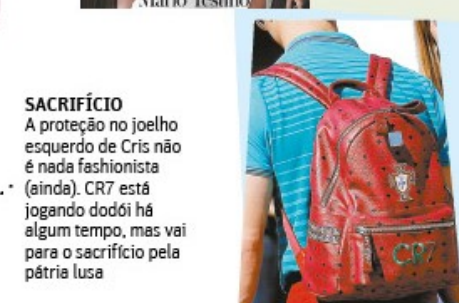
pátria lusa

QUALIDADE CR7 Ao contrário de outros jogadores. Cris usa mochilas CR7, a única
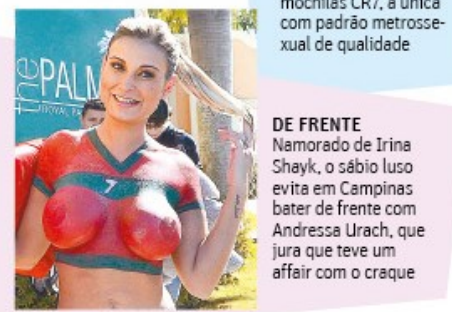

Fonte: Macedo (2014c)- Folha de São Paulo, 16 de junho de 2014, p. D2 e D3. 
Da proteção no joelho, à marca da mochila, a figura de Cristiano Ronaldo é representada evidenciando aquilo que é fútil, acessório, superficial e pouco masculino e, nesse processo que ridiculariza o homem atleta de futebol, os argumentos mais ínfimos são utilizados. "Se você vir Cris Ronaldo cobrindo o rosto, não são lágrimas. Ele tenta evitar que sua cútis tenha muito contato direto com raios ultravioleta". "Reza a lenda que para conservar seu tanquinho de escultura grega, Cris faz cerca de 3000 abdominais em casa em frente ao espelho, claro". "Cris nunca usou cuecas de Neymar ou Oscar Emboaba; veste apenas as CR7, com refrigeração exclusiva” (Macedo, 2014c, p. D2-D3).

Visibilizado como egocêntrico, extravagante e vaidoso, Cristiano Ronaldo, apesar de seus envolvimentos afetivo/sexuais com belas mulheres, um elemento distintivo das masculinidades heterocentradas, teria o 'péssimo hábito' de se tornar o centro das atenções, deixando em segundo plano, até mesmo, a beleza e sensualidade das mulheres com as quais se relaciona. Desse modo, "Copa e Cozinha" anuncia: "Dia da noiva? Só se for para as outras noivas! Em capa [...] com a namorada Irina Shayk, Cris Ronaldo deu um jeito de aparecer mais que a modelo russa" (Macedo, 2014c, p. D2 e D3).

De acordo com a "Folha", o palco por onde Cristiano Ronaldo atua extrapola os limites do gramado, como sinalizado por Macedo na publicação de 16/06/2014. Acusado de estar mais preocupado com sua imagem do que com o futebol que desempenha, o jogador português é frequentemente evidenciado "em seu modo pouco discreto de ser". Assim, ao pintar as unhas do pé (Extra, 2016), ao decidir jogar com chuteiras em estilo pouco convencional (Globo Esporte, 2018), ao mirar-se constantemente no espelho e nos telóes dos estádios, Cristiano Ronaldo tensiona alguns códigos de conduta ensinados pelo esporte, cujo efeito parece disparar um movimento que tenta coibir a transgressão e reafirmar socialmente aquilo que se entende por adequado para um homem atleta de futebol (Gastaldo, 2010). Por meio de Cristiano Ronaldo e da coluna Copa e Cozinha, o Jornal a Folha de São Paulo coloca em funcionamento uma tecnologia que é acionada pelas (más) condutas dos jogadores, a "tecnologia da zuação" (Sales \& Paraíso, 2013).

Concebida como um aparato de regulação das condutas (Sales \& Paraíso, 2013), no caso deste estudo, a tecnologia da zuação toma as masculinidades como objeto e a heteronormatividade como saber que informa e naturaliza a sequência sexo-gênero-sexualidade como norma. A heteronormatividade, portanto, designa, estabelece e sistematiza as normas, bem como as zonas de normalidade nas quais as condutas devem se posicionar. Apoiada nos princípios de comparação entre os sujeitos e de prescrição das condutas de gênero e sexualidade, a tecnologia da zuação age evidenciando as diferenças e produzindo determinados tipos de masculinidade como desejáveis e outras tantas como risíveis. Para tanto, faz uso de técnicas como o deboche, a ironia, a paródia, o sarcasmo, o repúdio e o banimento quando os homens não se atentam aos limites estabelecidos pela heteronoma (Sales \& Paraíso, 2013). A tecnologia da zuação, portanto, estabelece ao mesmo tempo um regime de "vigilância" e "sanção normalizadora" (Foucault, 2010), utilizando como recurso o que culturalmente se convencionou a associar como próprio das mulheres e dos homens gays. Apoiada nos regimes de verdade da heterossexualidade, a zuação responde a um regime regulatório e excludente que, por meio de práticas cotidianas e minuciosas, prescreve e determina no detalhe as condutas masculinas.

Em meio a esse mecanismo, a coluna "Copa e Cozinha" parece funcionar como instrumento das masculinidades cúmplices, condição de sujeito que não atende aos predicados das masculinidades hegemônicas gestadas no esporte, mas que por estarem apropriadas e fidelizadas a seus sentidos e significados são investidas do direito de veiculá-las e performatizá-las (Camargo, 2014). Mediante essa condição, Copa e Cozinha se investe da posição dos "zuadores" que outorgam para si a faculdade de colocar na condição de risível aqueles que atentem contra as condutas consideradas adequadas (Gastaldo, 2010).

Desse modo, ao acentuar marcas, ao exorbitar características atribuídas a Cristiano Ronaldo, o jornal invoca o riso pelo 'excesso'. A 'chacota' posta em funcionamento pela paródia ${ }^{5}$, coloca em evidência as fronteiras do que é adequado e inadequado para os homens. Assim, reifica pelo deboche, repete, por meio da 
"brincadeira" e da "zuação", a discrição e o comedimento como característica idealizadas como 'essenciais' da hombridade.

Entre o conveniente e o excessivo da Copa do Mundo de 2014, a coluna "Copa e Cozinha" constituise, portanto, como espaço de vigília e censura com vistas à manutenção dos códigos de masculinidade e das hierarquias de gênero e sexualidade prescritos pelo currículo do Futebol.

Esse processo que atribui foco ao inapropriado dá vistas a uma pedagogia que sugere desqualificar aqueles que ousam transpor fronteiras de gênero, ainda que esse sujeito se beneficie de prerrogativas concedidas a homens como Cristiano Ronaldo.

\section{TECENDO CONSIDERAÇÕES}

Terreno fértil para compreensão e análise de diversos fenômenos sociais, neste texto, o jornal Folha de São Paulo permitiu problematizar as representações de masculinidade no futebol a partir das publicações que evidenciam a dissonância de gênero atribuída ao jogador da seleção portuguesa Cristiano Ronaldo.

Modelo de grifes como Empório Armani, Nike e de sua própria marca de roupas, calçados e perfumes (CR7), Cristiano Ronaldo se constituiu como um dos atletas de futebol mais populares das redes sociais Facebook e Instagram, além de ser figura corrente nos diversos meios de comunicação, que vão do jornalismo esportivo às revistas e sites de fofoca. Na Folha de São Paulo, alvo constante de ironias e "zuações".

No decorrer da cobertura da Copa do Mundo FIFA/Brasil/2014, as representações de masculinidade dissonante estiveram vinculadas ao não sério e, especificamente acerca das publicações sobre "Cris Ronaldo", estiveram circunscritas a uma coluna especialmente produzida para comentar com irreverência os acontecimentos da Copa. Nesse processo, a coluna "Copa e Cozinha” faz uso da zuação como um aparato que avalia, qualifica e julga a conduta inapropriada e excessiva do atleta português, tecnologia que tem como finalidade a regulação das condutas e a manutenção de hierarquias de gênero. Nesse processo, a "tecnologia da zuação" evidencia o "inadequado" ao mesmo tempo que intenciona suavizar a ofensa, pelo riso e assim repete e reforça as tradicionais referências de gênero no esporte.

Mesmo sendo alvo constante de zombarias, a figura de Cristiano Ronaldo, como dito, não deve ser concebida como marginal, excêntrico ou abjeto, afinal goza de inegáveis prerrogativas decorrentes do locus social que ocupa. Apesar disso, a "zuação" que incide sobre a postura vaidosa e pouco discreta do atleta português funciona como produção cultural que inibe e constrange outras possibilidades de identidade de gênero no esporte.

\section{REFERÊNCIAS}

Anjos, L. A. (2015). Vôlei masculino é para homens: Representações do homossexual e do torcedor a partir de um episódio de homofobia. Movimento, 21(1), 11-24. doi: https://10.22456/1982-8918.43189

Bandeira, G. A. (2010). Um currículo de masculinidades nos estádios de futebol. Revista Brasileira de Educação, 15(44), 342-351. doi: https://10.1590/S1413-24782010000200010

Berger, C. (2002). Do jornalismo: toda notícia que couber, o leitor apreciar e o anunciante aprovar, a gente publica. In: Porto SD, organizador. O Jornal: da forma ao sentido. 2. ed. Brasília: Editora Universidade de Brasília.

Brum, A., Capraro, A. M. (2015). Mulheres no Jornalismo Esportivo: uma 'visão além do alcance'? Movimento, 21(4), 959-971. doi: https://10.22456/1982-8918.52730

Camargo, W. (2014). Notas etnográficas sobre vestiários e a erotização de espaços esportivos. Revista Artemis, 17(1), $61-75$.

Camargo, W. X. (2016). Dilemas insurgentes no esporte: as práticas esportivas dissonantes. Movimento , 22(4), 1337-1350. doi: https://10.22456/1982-8918.66188 
Dal'igna, M. C. (2011). Família S/A: um estudo sobre a parceria família-escola. (Tese de Doutorado em Educação). Universidade Federal do Rio Grande do Sul, Programa de Pós-Graduação em Educação, Porto Alegre.

Damo, A. D., y Oliven, R. G. (2013). O brasil no horizonte dos megaeventos esportivos de 2014 e 2016: sua cara, seus sócios e seus negócios. Horizontes Antropológicos, 19(40), 19-63. doi: https://10.1590/S0104-7183201300020 0002

Extra. (2016). CR7 é flagrado com as unhas do pé pintadas de preto durante férias nos Estados Unidos. Globo.com, 01 de agosto de 2016. Recuperado de https://extra.globo.com/esporte/cr7-flagrado-com-as-unhas-do-pe-pinta das-de-preto-durante-ferias-nos-estados-unidos-19824473.html

Figueiredo, P. K. (2013). A Serviço da Belleza: Imagens Fotográficas em Cienarte e Scena Muda (1921-1941). Atos de Pesquisa em Educação, 8(1), 306-337. doi: https://10.7867/1809-0354.2013v8n1p306-337

Folha De São Paulo. (2020) Copa e Cozinha. Perfil. Recuperado de https://copaecozinha.blogfolha.uol.com.br/perfil/

Foucault, M. (2010). Vigiar e Punir: História da violência nas prisões. Petrópolis: Vozes.

Gastaldo, E. (2009). “O país do futebol” mediatizado: mídia e Copa do Mundo no Brasil. Sociologias, 11(22), 352-369. doi: https://10.1590/S1517-45222009000200013

Gastaldo, É. (2010). As relações jocosas futebolísticas: futebol, sociabilidade e conflito no Brasil. Mana, 16(2), 311-325. doi: https://10.1590/S0104-93132010000200003

Globo Esporte. (6, março, 2018). Cristiano Ronaldo estreia nova chuteira inspirada no animal mais veloz do mundo. Globo.com. Recuperado de https://globoesporte.globo.com/blogs/brasil-mundial-fc/post/2018/03/06/cristian o-ronaldo-estreia-nova-chuteira-inspirada-no-animal-mais-veloz-do-mundo.ghtml

Goellner, S. V. (2003). Bela, maternal e feminina: imagens da mulher na Revista Educação Physica. Ijuí: Unijuí.

Goellner, S. V. (2005). Mulheres e futebol no Brasil: entre sombras e visibilidades. Revista Brasileira de Educação Física e Esporte, 19(2), 143-151. doi: https://10.1590/S1807-55092005000200005

Hall, M., y Gough, B. (2011). Magazine and reader constructions of 'metrosexuality' and masculinity: a membership categorisation analysis. Journal of Gender Studies, 20(1), 67-86. doi: https://10.1080/09589236.2011.542023

Hall, M., Gough, B., y Seymour-Smith, S. (2012). “I’m METRO, NOT Gay!”: A Discursive Analysis of Men's Accounts of Makeup Use on YouTube. The Journal of Men's Studies, 20(3), 209-226. doi: https://10.3149/jm s.2003.209

Hall S, organizador. (1997). Representation. Cultural representation and cultural signifying practices. London: Thousand Oaks/New Delhi: Sage/Open University.

Kuhn Junior, N., Castilhos, D., Montin, J. M., Sanfelice, G. R. (2015). Framing the 2013 FIFA Confederations Cup Finals by the Folha de São Paulo Newspaper. American International Journal of Contemporary Research, 5(4), $18-26$.

Lopes, M. C. (2009). Políticas de inclusão e governamentalidade. Educação \& Realidade, 34(2), 153-169.

Louro, G. L. (2008). Gênero e sexualidade: pedagogias contemporâneas. Pro-Posições, 19(2), 17-23.

Macedo, S. (17, Jun, 2014d). Confira como foi a seleção alemã na "era Schumacher". Folha de São Paulo, São Paulo, p. D2. Recuperado de https://copaecozinha.blogfolha.uol.com.br/2014/06/17/confira-como-foi-a-selecao-ale ma-na-era-schumacher/

Macedo, S. (12, Jun, 2014a). Faça Sua Tabela. Folha de São Paulo, São Paulo, p. D2. Recuperado de https://www1.f olha.uol.com.br/fsp/esporte/174126-monte-sua-tabela.shtml

Macedo, S. (16, Jun, 2014c). Isso é Cris Ronaldo. Folha de São Paulo, São Paulo, p. D2, D3. Recuperado de https://w ww.folha.uol.com.br/fsp/esporte/174126-isso-e-cris-ronaldo.shtml

Macedo, S. (13, Jun, 2014b). Sexta-feira, 13: o terror da Copa. Folha de São Paulo, São Paulo, p. D2. Recuperado de h ttps://copaecozinha.blogfolha.uol.com.br/2014/06/13/sexta-feira-13-o-terror-na-copa/

Macedo, S. (18, Jun, 2014e). Veja um resumão da primeira rodada da Copa. Folha de São Paulo, São Paulo, p. D2. Recuperado de https://copaecozinha.blogfolha.uol.com.br/2014/06/18/veja-um-resumao-da-primeira-rodada -da-copa/ 
Meyer, D. E., Klein, C., Dal'Igna, M. C., y Alvarenga, L. F. (2014). Vulnerabilidade, gênero e políticas sociais: a feminização da inclusão social. Revista Estudos Feministas, 22(3), 885-904. doi: https://10.1590/\%x

Mezzaroba, C., Messa, F. C., y Pires, G. L. (2011). Quadro teórico-conceitual de referência: megaeventos e o agendamento midiático-esportivo. In: Pires, G. L., organizador. O Brasil na Copa, a Copa no Brasil: registros de agendamento para 2014 na cobertura midiática da Copa da África do Sul. Florianópolis: Tribo da Ilha. p. 21-45.

Oliveira, R. (3, Jul., 2014). Benza Deus. Folha de São Paulo, São Paulo, p. D10. Recuperado de https://www1.folha. uol.com.br/fsp/esporte/174126-benza-deus.shtml

Ronaldo, C. (2020). Cristiano Ronaldo. Recuperado de www.cristianoronaldo.com

Sabat, R. (2001). Pedagogia cultural, gênero e sexualidade. Revista Estudos Feministas, 9(1), 4-21. doi: https://10.15 90/S0104-026X2001000100002

Sales, S. R., y Paraíso, M. A. (2013). O Jovem macho e a Jovem Difícil: governo da sexualidade no currículo. Educação \& Realidade, 38(2), 603-625. doi: https://10.1590/S2175-62362013000200015

Sanfelice, G. R. (2018). Processos midiáticos no campo esportivo. Curitiba: Appris.

Santana, F. C., y Monteiro, L. F. (2014). Entre sinhás e nhonhôs: uma leitura da criadagem doméstica a partir da literatura de civilidade luso-brasileira (1840-1889). In: IV Congresso Internacional de História, Jataí.

Schpun, M. R. (1999). Beleza em jogo: cultura física e comportamento em São Paulo nos anos 20. São Paulo: Editora SENAC São Paulo.

Scott, J. (1995). Gênero: uma categoria útil de análise histórica. Educação \& Realidade, 2(20), 71-100.

Silva, A. M. (2014). Entre o corpo e as práticas corporais. Arquivos em Movimento, 10(1), 5-21.

Villar M. (2010). Batuque na Cozinha: estudo sobre os espaços de cozinhar no Brasil Colônia, através dos relatos de viajantes. (Dissertação de Mestrado em Arquitetura e Urbanismo). Universidade de Brasília, Programa de PósGraduação em Arquitetura e Urbanismo, Brasília.

\section{Notas}

1 O “júri” responsável pela eleição dos “musos da copa” teria sido composto pelos cantores Juliana Valadrares, Camilla Castro, Fafá de Belém, Roberta Miranda, Wanderleia e Luiz Ayrão; pelas atrizes Ana Kutner e Andre de Nóbrega; pelo sambista Thobias da Vai-Vai, pela humorista Nany People e por Victor Larguesa do Canal das Bee (OLIVEIRA, 2014).

2 No artigo "Atenção: Câmera ligada", Eliane Brum (2014, p. D10) evidencia os desejos das fã̃s: "Hulk deixa eu apertar sua bunda"

3 Sandro Macedo é autor do livro "Diário de uma Conquista”, sobre o título mundial de Clubes do Corinthians no Japão em 2012 (FOLHA DE SÃO PAULO, 2020).

4 Categoria identitária compreendida como uma mudança no modo como alguns homens passam a conceber o auto cuidado e as práticas de embelezamento (HALL; GOUGH; SEYMOUR-SMITH, 2012).

5 Paródia, neste texto, não deve ser entendido como uma produção ficcional a partir do real, mas um modo de representação, um recurso que coloca em funcionamento relações de gênero. Assim, o que interessa argumentar não é a 'verdade' ou 'mentira' de Cristiano Ronaldo, mas o modo como o recurso da paródia permite reafirmar um código de conduta sobre aquilo que é adequado e desqualificado nas performances de gênero no campo do futebol (LOURO, 2008; BUTLER, 2003). 